\title{
Development and Experimental Validation of a Dynamic Thermal and Water Distribution Model of an Open Cathode Proton Exchange Membrane Fuel Cell
}

\author{
Stephan Strahl, Attila Husar, Maria Serra ${ }^{1}$ \\ Institut de Robòtica i Informàtica Industrial (CSIC-UPC), Parc Tecnològic de Barcelona. C/ Llorens i Artigas 4-6. 08028 Barcelona. Spain.
}

\begin{abstract}
Water concentration in proton exchange membrane (PEM) fuel cells strongly influences performance and durability which demands for fundamental understanding of water transport mechanisms. The system efficiency can be significantly improved with greater understanding of water flux dynamics through the membrane and its dependence on the internal conditions of the fuel cell. Therefore, a two-dimensional, non-isothermal, dynamic model of a $100 \mathrm{~W}$ open cathode, self-humidified PEM fuel cell system has been developed, that is capable of representing system specific control mechanisms for water and thermal management. The model consists of three coupled sub models based on energy, momentum and water mass balance of the system. The work is based on experimental observations of the investigated fuel cell stack, for which the crucial coefficients for water transport, namely the diffusion and the electroosmotic drag (EOD) coefficient have been determined. The diffusivity of water vapor through the MEA at $30{ }^{\circ} \mathrm{C}$ was determined to be $3.3 \times 10^{-8} \mathrm{~m}^{2} \mathrm{~s}^{-1}$ and increases by $3 \times 10^{-10} \mathrm{~m}^{2} \mathrm{~s}^{-1}$ per ${ }^{\circ} \mathrm{C}$ up to $50{ }^{\circ} \mathrm{C}$ stack temperature. The EOD coefficient was measured as 0.47 to 0.48 water molecules per proton at stack currents from 1 to 3 A. Validation of the steady state and the dynamic model by using experimental data, directly obtained from laboratory tests, has shown that the model predictions match the experimental data well.
\end{abstract}

Keywords: Proton exchange membrane fuel cells, Water transport, Electroosmotic drag, Water diffusion, Thermal management

\section{Introduction}

For the past 20 years astonishing progress in terms of PEM fuel cell materials, component design, production, and system power density improvements have been achieved. However, there is still a lot to be done in the field of fuel cell system controls, which makes it essential to understand the different physical phenomena within a fuel cell and how they need to be controlled in order to improve efficiency, operating range and durability. The hypothesis is that if the water movement within a PEM fuel cell could be controlled quickly to maintain optimal membrane water content and minimal liquid water, efficiency would be improved. As shown in the experiments of Springer et al. [1], membrane proton conductivity is a strong function of water content. Thus, the performance of PEM fuel cells is sensitive to membrane hydration. Although water is produced during the reaction, the anode catalyst layer is often dehydrated because water is dragged from the anode to the cathode by protons moving through the membrane, which is called electro-osmotic drag (EOD).

Besides the EOD, the main water transport mechanism in a PEM fuel cell is diffusion through the membrane due to concentration differences between anode and cathode. The third transport mechanism is hydraulic permeation, which is caused

\footnotetext{
${ }^{1}$ Corresponding author: Maria Serra Email: maserra@iri.upc.edu Te: +34934015751
}

by pressure difference. EOD always transports water from the anode to the cathode whereas diffusion can occur in both directions.

Water is needed to maintain good proton conductivity and therefore has to be kept in the membrane, however liquid water on the catalyst reduces the active area, and in the GDL it hinders the reactant gases from diffusing to the catalyst surface and thus reduces performance. The goal is to maintain an optimal water concentration in the membrane electrode assembly (MEA) by keeping a balance between the two conflicting requirements. Thus, to control water transport within a fuel cell system and thereby optimize the membrane hydration at any operation point, proper dynamic water management strategies have to be developed. This has recently been analyzed by Hussaini \& Wang [2].

In order to characterize, understand and manipulate the water transport mechanisms, experimental work is needed as well as a mathematical model that describes the physical phenomena [3].

A 2D isothermal model of the MEA of a PEM fuel cell including the influence of convection in the gas flow channels was developed by Gurau et al. [5]. This model accounts for the concentration variations along the interface between the gas diffusion layer and the catalyst layer, which is related to the gas transport in the coupled domain of the gas flow channel and the gas diffusion layer. However, fluid dispersion in the porous media is disregarded.

The amount of waste heat produced by a PEM fuel cell is 


\section{Symbols}

\begin{tabular}{|c|c|c|}
\hline$\ldots$ & Cross-sectional area & {$\left[m^{2}\right]$} \\
\hline$c \quad \ldots$ & Concentration & {$\left[\mathrm{mol} \mathrm{m}^{-3}\right]$} \\
\hline$C_{p} \quad \ldots$ & Specific heat capacity $\ldots .$. & {$\left[\mathrm{J} \mathrm{mol}^{-1} \mathrm{~K}^{-1}\right]$} \\
\hline$D \quad \ldots$ & Diffusion coefficient & {$\left[m^{2} s^{-1}\right]$} \\
\hline$\epsilon \ldots$ & EOD coefficient & {$[1]$} \\
\hline$\ldots$ & Efficiency & {$[1]$} \\
\hline$\Phi_{H 2 O}$ & Water mass flux & {$\left[k g s^{-1} m^{-2}\right]$} \\
\hline$\Phi_{q}$ & Heat flux & {$\left[W m^{-2}\right]$} \\
\hline$H_{L H V}$ & Lower heating value $H_{2}$ & {$\left[k J \mathrm{~mol}^{-1}\right]$} \\
\hline$I \quad \ldots$ & $\ldots \ldots \ldots \ldots \ldots$ & {$[A]$} \\
\hline$J$ & Molar flux & {$\left[\mathrm{mol} \mathrm{s}^{-1} \mathrm{~m}^{-2}\right]$} \\
\hline$k \quad \ldots$ & Thermal conductivity $\ldots .$. & {$\left[W m^{-1} K^{-1}\right]$} \\
\hline$\kappa \ldots$ & Permeability & {$\left[m^{2}\right]$} \\
\hline$M \quad \ldots$ & Molar mass $\ldots$ & {$\left[\mathrm{kg} \mathrm{mol}^{-1}\right]$} \\
\hline$m \quad \ldots$ & Mass & {$[\mathrm{kg}]$} \\
\hline$\dot{m} \quad \ldots$ & Mass flow rate & {$\left[\mathrm{kg} \mathrm{s}^{-1}\right]$} \\
\hline$\mu \quad \ldots$ & Dynamic viscosity & {$[P a s]$} \\
\hline$n_{b p p}$ & Number of bipolar plates $\ldots$ & {$[1]$} \\
\hline$n_{\text {cell }}$ & Number of cells & {$[1]$} \\
\hline$n_{c p p}$ & Number of channels per plate & {$[1]$} \\
\hline$P \quad \ldots$ & Pressure $\ldots$ & {$[P a]$} \\
\hline$Q \quad \ldots$ & Heat energy & {$[W]$} \\
\hline$\ldots$ & Density & {$\left[\mathrm{kg} \mathrm{m}^{-3}\right]$} \\
\hline$T \quad \ldots$ & Temperature & {$[K]$} \\
\hline$t \quad \ldots$ & Time & {$[s]$} \\
\hline 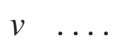 & Velocity & {$\left[m s^{-1}\right]$} \\
\hline$V_{\text {stack }}$ & Stack voltage & {$[V]$} \\
\hline$W$ & Work & {$[W]$} \\
\hline$x_{\mathrm{H} 2 \mathrm{O}}$ & Humidity mass ratio & {$[1]$} \\
\hline
\end{tabular}

similar to its electrical power output, depending on its voltage. Moreover it only tolerates a small temperature deviation from its design point for best performance, stability and durability. Therefore a three-dimensional, non-isothermal model was developed by Ju et al. [6]. The model accounts for various heat generation mechanisms and combines them with the electrochemical and mass transport models. A three-dimensional, non-isothermal, two-phase flow model was developed by Wang and Wang [7], which was applied by Basu et al. [8] in order to study the phase-change phenomena in the cathode GDL of a PEM fuel cell and has finally been extended to a complete twophase model for an entire PEM fuel cell, including two phase flow in the gas channels, by Basu et al. [9].

Similar to the model of Gurau et al. [5], but considering fluid dispersion in the porous media, two modeling modes of a 2D isothermal model have already been implemented in COMSOL Multiphysics by Shi \& Wang [10]. As defined in figure 1 the computational domain of a 2D model can either be a partial cross-section parallel (x-z-direction) or perpendicular (y$\mathrm{z}$-direction) to the gas flow direction in the gas channel. The

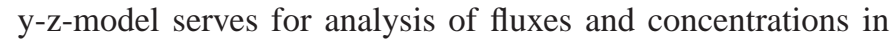
the gas diffusion and catalyst layers and includes the effect of ribs or lands between the channels. This model is also used for investigating fuel cells with interdigitated flow patterns. If

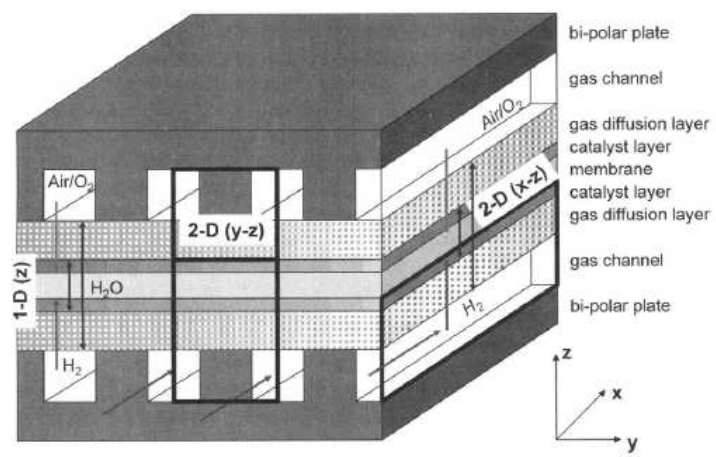

Figure 1: 1D and 2D modeling domains for a PEM fuel cell [4]

the field of study concentrates on the analysis of reactant gases and water vapor concentration along the channel, the $\mathrm{x}$-z-model is preferred. The two models can be combined to describe the overall behavior of PEM fuel cells in all directions, as shown by Shi \& Wang [10].

The water transport equations in most of these models are based on the ex situ water transport experiments of a Nafion 117 membrane performed by Springer et al. [1]. These experiments have created a baseline for the industry and show the relationship between EOD and water diffusion through the membrane with respect to membrane water activity and membrane temperature. Even though the diffusion and EOD data for the membrane were accurate, direct application of such data to a real fuel cell may not be appropriate due to the fact that this data was collected ex situ, and can not be considered constant because the coefficients vary significantly depending on the membrane type and on the operating conditions, such as temperature. In situ experiments of Husar et al. [11] showed that the EOD of a Nafion 115 membrane increases significantly with temperature and current density and that water diffusivity of membrane is lower than reported by Springer et al. [1].

A recently published review of water balance in the MEA by Dai et al. [3] states that further work is needed to better understand the fundamentals of water transport in the MEA, not

\section{Subscripts}

\begin{tabular}{|lcl|}
\hline act & $\ldots \ldots \ldots$ & active \\
an & $\ldots \ldots \ldots$ & anode \\
ca & $\ldots \ldots \ldots$ & cathode \\
ch & $\ldots \ldots \ldots$ & channel \\
cons & $\ldots \ldots$ & consumed \\
$d$ & $\ldots \ldots \ldots$ & dry \\
$d p$ & $\ldots \ldots \ldots$ & dew point \\
el & $\ldots \ldots \ldots$ & electrical \\
gen & $\ldots \ldots \ldots$ & generated \\
in & $\ldots \ldots \ldots$ & inlet \\
$m$ & $\ldots \ldots \ldots$ & measured \\
out & $\ldots \ldots \ldots$ & outlet \\
sc & $\ldots \ldots \ldots$ & short circuit \\
tot & $\ldots \ldots \ldots$ & total \\
\hline
\end{tabular}


only to improve performance, but also to develop new materials for better water management and to improve durability. In order to develop and simulate dynamic water management strategies that match the application load requirements and the operating conditions, new models need to be based on a broad understanding of water transport in the MEA.

This article describes the developed dynamic thermal and water distribution model, as well as the performed experimental work and the model validation of an open cathode, selfhumidified PEM fuel cell.

\section{Specific stack characteristics}

This work treats the modeling of the water and heat transfer of the commercially available 100W PEM fuel cell system H-100 from Horizon Fuel Cells. This open cathode system is self-humidified and air cooled. It includes a cooling fan directly attached to the fuel cell housing, which removes heat from the stack by forced convection and at the same time provides oxygen to the cathode. The anode system has electromagnetic valves on both the inlet and outlet. The outlet valve is usually closed and the pressure is controlled by a forward pressure regulator. It mainly runs in a dead-ended mode, however a periodical hydrogen purge removes water and nitrogen that has crossed over from the cathode that would otherwise hinder the transport of reactant gas to the catalyst layer. A very quick short circuit is applied to the fuel cell to create water and heat to the cathode catalyst. With the manufactures' controller the interval of the hydrogen purge and the short circuit is independent of the stack conditions. This means that even if the fuel cell does not require a purge or a short circuit, the system performs it anyway, which reduces efficiency. In order to increase efficiency, without reducing the robustness or operating range of the system, a broad understanding of the water transport inside the fuel cell is necessary, which can be studied by the developed model.

\section{Model description}

\subsection{Modeling Strategy}

The developed model is used to simulate and study the effects of the dynamic control mechanisms for water management, namely the fan, the periodical hydrogen purge and the short circuit to relate them to the fuel cell performance. By controlling the concentration of water vapor and the additional creation of water due to the short circuit, membrane hydration and fuel cell flooding can be managed. As water distribution and transport is dependent on temperature the model has to include not only the mass balance but also the energy balance of the H-100 fuel cell system. Since this model concentrates on the water transport within the cell, the current density distribution is not modeled. In order to facilitate the model, the current density at the cathode catalyst layer is assumed to be constant in the direction along the flow channel.

To visualize the simulation results, the mathematical model is implemented in COMSOL Multiphysics, a finite element analysis software environment. By means of COMSOL the model can be solved numerically for the specific geometry.

The trade off between accuracy and computing capacity should be considered in choosing the model dimension. Within this work a 2D model is developed that provides better simulation accuracy than 1D models and has a higher computational efficiency than 3D models, which also already exist in the literature [6], [7], [9].

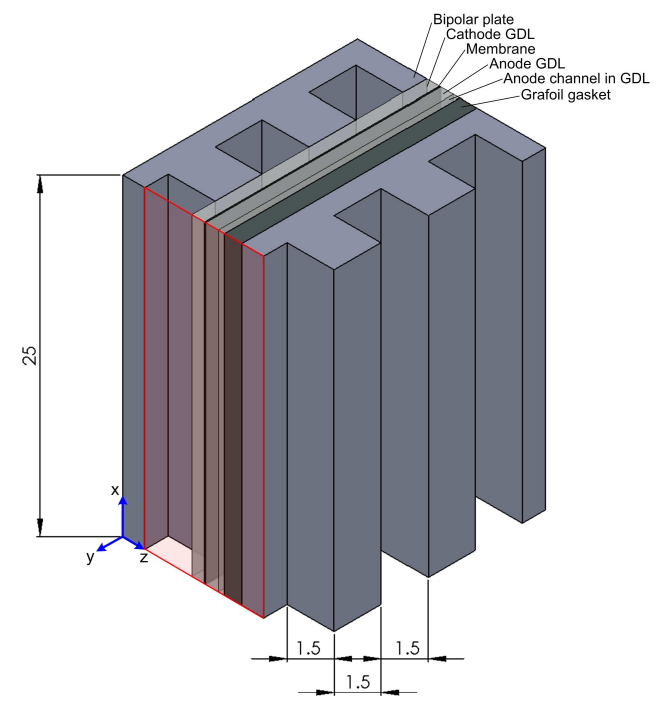

Figure 2: H-100 stack configuration and modeled section

Referring to figure 2, the 2D model describes water and heat propagation and distribution in the $\mathrm{x}$-Z-cross-section of a single cell within the stack. The cross-section can either go through a rib of a bipolar plate or through a channel. Since the primary objective of the model is to describe the effects of water transport, the air mass flow through the channel plays an important role and so the second option for the cross-section location is chosen. A 2D thermal analysis in the y-z-cross-section has shown that the temperature difference at the channel walls in the same plane is negligible, due to the relatively high thermal conductivity of the solid sections and the fully developed flow through the channel. Thus, the heat removal through the two land sides of one channel, that do not appear in the 2D model in the $\mathrm{x}$-Z-cross-section, is assumed to be equal to the heat removal through the other two channel walls. This simplification is valid in this model, because the channel is square and the thickness of the land is equal to the side of the square, as shown in figure 2. Considering also that the X-Z-model is infinite in the y-direction, which means that there is an infinite channel without any land, the effective heat removal area in both models is equal. Thus the overall heat removal from the cell can be modeled by just one 2D model in the $\mathrm{x}$-Z-cross-section.

Figure 3 shows the geometry in the x-z-plane of the modeled cell within the H-100 stack referred to the cross-section marked in red in figure 2. The modeled sub-domains for the simulation of water propagation and distribution are the cathode flow channel, the cathode GDL (including a microporous layer) and two 


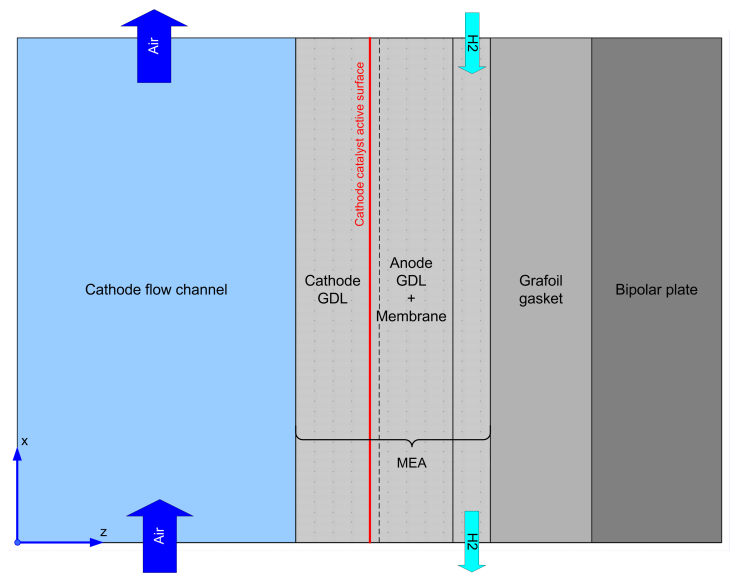

Figure 3: Model geometric subdomains

anode GDL's (including a microporous layer). To simulate the heat transfer within the cell, the Grafoil gasket and the bipolar plate also have to be considered, due to conductive heat transfer. The right boundary of the bipolar plate is equal to the left boundary of the cathode flow channel in terms of heat transfer, because only one repeating unit of the stack is modeled.

In terms of modeling, the material properties and dimensions of the components, as well as the anode channel configuration have to be known. The thicknesses of the different layers are listed in table 1 . The channel length is $25 \mathrm{~mm}$.

\begin{tabular}{lc}
\hline Component & Thickness $[\mathrm{mm}]$ \\
\hline Bipolar plate web & 0.70 \\
Grafoil gasket & 0.55 \\
Anode GDL (flow channel) & 0.20 \\
Anode GDL (cover) & 0.20 \\
Microporous layer & 0.20 \\
Membrane & 0.05 \\
Cathode GDL & 0.20 \\
Cathode flow channel & 1.50 \\
\hline
\end{tabular}

Table 1: H-100 component thicknesses

Since the material of the membrane is unknown, a bulk diffusion coefficient for the whole MEA was determined experimentally. The MEA on the cathode side includes the GDL and the microporous diffusion layer and the cathode catalyst layer. On the anode side the MEA includes the membrane, anode catalyst layer, microporous diffusion layer, and two GDL's. To clarify, the membrane is included in the first anode GDL, which is denoted by the dashed line in figure 3. Thus, in terms of water transport and generation the more important cathode catalyst boundary still remains.

According to the model geometry, figure 4 shows a schematic of the different physical phenomena that occur within the fuel cell, how they are coupled to each other and how they are treated in the model.

The heart of the model is the water transport sub model, which describes the distribution of water vapor concentration in the MEA and the flow channels. In order to describe convective transport, the water transport sub model is coupled to the momentum transport sub models of anode and cathode, which themselves are linked with the water transport sub model because the density of the reactant gases is dependent on the amount of water in the gas. Since density is also dependent on temperature, the energy transport sub model has to be included, as well. As shown in section 4, the diffusion coefficient is also a function of temperature, which links the diffusive mass transport to the temperature distribution. The water transport from anode to cathode due to the electroosmotic drag effect is a function of the stack current, which is set by the external load.

The energy transport model, which describes the temperature distribution within the cell not only includes conductive heat transfer through the MEA, the grafoil gasket and the bipolar plate, but also the convective cooling by the fan. Therefore it is coupled to the velocity field in the cathode channel, obtained by the momentum transport sub model, as described in section 3.2.2.

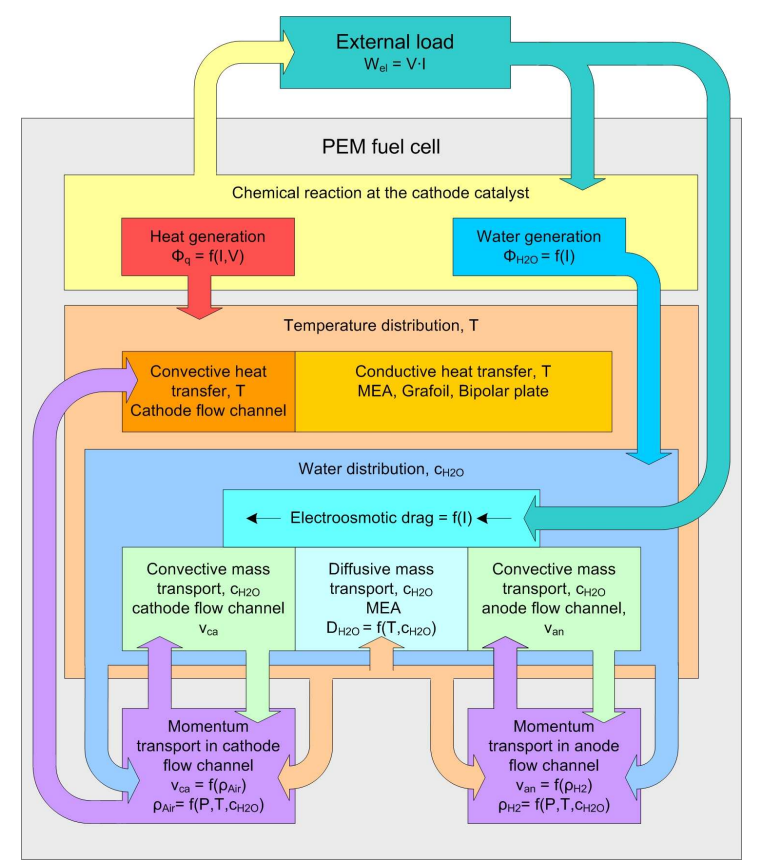

Figure 4: Model schematic

Depending on the external load, a certain amount of heat and water is generated at the cathode catalyst surface due to the electrochemical reaction. This generation can be described by the stack current and voltage that is set by the external load. The resulting fluxes of water and heat are treated as an input to the water and energy transport sub model, respectively. The different sub models are explained in the following sections.

A further sub model that describes charge transfer and polarization curve affected by the different types of voltage losses is not included in this work, because the needed parameters to determine voltage losses, such as exchange current density and charge transfer coefficient, are difficult to validate with in situ testing.

This model considers that water enters and exits the fuel cell 
in the vapor state on both anode and cathode. Regarding the cathode, water vapor that enters the cell has the relative humidity of the environment. On the cathode outlet there is always a stoichiometry greater than ten that does not allow the gas to reach $50 \%$ relative humidity at an outlet gas temperature of approximately $45^{\circ} \mathrm{C}$, which has also been verified by experiments. Thus, a single-phase model on the cathode side is accurate. The only controversial part would be the anode where the water could condense. Since the anode reaction is orders of magnitude faster than the cathode reaction and hydrogen's diffusivity is much higher than oxygen's, the effects of liquid water on the anode can be neglected for the sake of model simplification. So the model properly predicts water and temperature distribution in the flow channels and the GDL, even without including two-phase flow.

Table 2 shows how the COMSOL application modes are applied to the specific subdomains. These application modes are linked to the different submodels, which are explained in the following section.

\subsection{Mathematical model description}

\subsubsection{Energy transport}

The amount of energy brought into the fuel cell system is given by the lower heating value of hydrogen, because it is assumed that all of the product water leaves the stack as vapor. The energy output is split into electrical energy and heat, thus the energy balance of the system is given by:

$$
W_{H_{2}}=W_{e l}+Q_{t o t}
$$

The total generated heat $Q_{t o t}$ can be determined using the fuel cell efficiency, which is defined by the ratio of the energy output and the energy input of the system. According to equation 1 this is the ratio of useful electrical work and the work of the consumed hydrogen:

$$
\eta=\frac{W_{e l}}{W_{H_{2}}}
$$

The work of the consumed dry hydrogen at $25^{\circ} \mathrm{C}$ can be calculated using hydrogen's lower heating value [4]:

$$
W_{H_{2}}=\frac{H_{L H V}}{2 \cdot F} \cdot I \cdot n_{\text {cell }}
$$

Combining equations 2 , and 3 leads to the fuel cell stack efficiency:

$$
\eta_{L H V, \text { stack }}=\frac{V_{\text {stack }}}{1.254 \cdot n_{\text {cell }}}
$$

Current and voltage values that are used to calculate efficiency are obtained by in-house experimental data of the studied fuel cell stack. The stack efficiency can then be used to describe the total generated heat energy by including equation 4 into 1 :

$$
Q_{t o t}=W_{H_{2}}-W_{e l}=W_{e l} \cdot\left(\frac{1}{\eta_{L H V, s t a c k}}-1\right)
$$

Assuming that all the generated heat energy is released on the cathode catalyst layer, the heat flux through this boundary is determined by the generated heat divided by the active area:

$$
\Phi_{q}=\frac{Q_{t o t}}{A_{a c t}} \quad\left[W m^{-2}\right]
$$

Heat is transferred by two mechanisms within the fuel cell. The cathode flow channel is dominated by forced convection due to the fan, whereas the heat transfer through the MEA and the bipolar plate is mainly by conduction, which can be seen in the heat transfer simulation results in figure 5. Although there is also convection due to the diffusing reactants, this transport can be considered negligible because of the high thermal conductivity of the GDL material [6].

Several thermal analyses and models of non-insulated PEM fuel cells e.g. by Müller \& Stefanopoulou [12] have shown that the heat loss to the environment by convection and radiation is between 10 and $20 \%$ of the total waste heat. Since the fuel cell stack used to validate the model is encased in a plastic support structure, it is assumed that the heat loss to the environment is minimal and thus neglected. Therefore, only heat removal from the system by convective heat transport through the cathode gas channel is considered.

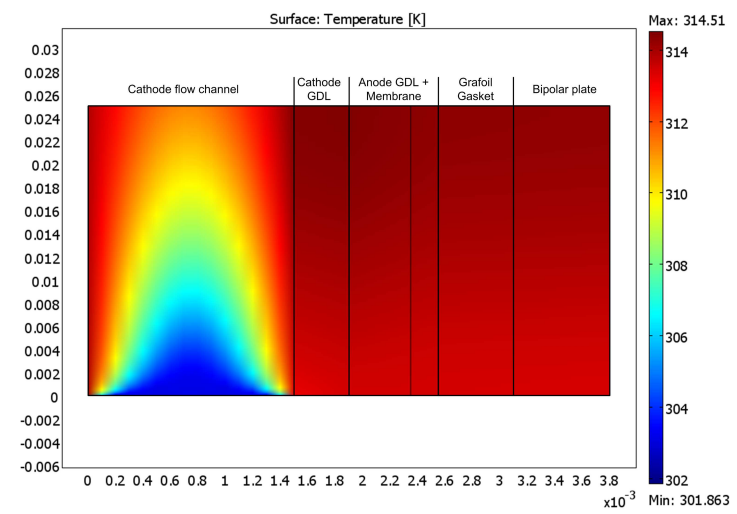

Figure 5: Typical temperature distribution in the cell and the cathode flow channel ( $\mathrm{x}$ and $\mathrm{y}$ axis dimensions are in meters)

Using conservation of energy, the heat equation that describes conduction and convection within the fuel cell results in [4]:

$$
\left(\rho C_{p}\right) \cdot \frac{\delta T}{\delta t}+\left(\rho C_{p}\right) \cdot \vec{v} \cdot \nabla T=\nabla(k \cdot \nabla T)+S_{e}
$$

The first term of the left-hand side describes the heating rate and the second term the heat flux due to convection. The first term on the right-hand side accounts for conductive heat flux through the media with the thermal conductivity $k$, described by Fourier's law. The source term $S_{e}$ represents heat flux due to other heat sources or sinks, which in this case is the source heat flux through the catalyst surface, described by equation 6 .

The velocity vector $\vec{v}$ is obtained by solving the NavierStokes equation for momentum transport within the cathode flow channel, which is explained in section 3.2.2. 


\begin{tabular}{l|c|c|c|c}
\hline & $\begin{array}{l}\text { General } \\
\text { heat transfer }\end{array}$ & $\begin{array}{l}\text { Incompressible } \\
\text { Navier-Stokes }\end{array}$ & Darcy's law & $\begin{array}{l}\text { Convection } \\
\text { Diffusion }\end{array}$ \\
\hline Cathode flow channel & $\mathrm{X}$ & $\mathrm{X}$ & $\mathrm{X}$ \\
Cathode GDL & $\mathrm{X}$ & & $\mathrm{X}$ \\
Andoe GDL + membrane & $\mathrm{X}$ & $\mathrm{X}$ & $\mathrm{X}$ \\
Anode channel in GDL & $\mathrm{X}$ & $\mathrm{X}$ & $\mathrm{X}$ \\
Bipolar plate + Grafoil & $\mathrm{X}$ & & \\
\hline
\end{tabular}

Table 2: COMSOL application modes used in the different model subdomains

The input parameters of the model are the inlet air temperature of the cathode, which is necessary to determine the heat removal from the cell by convection, as well as the cell voltage and current that are used to calculate heat generation at the cathode catalyst as already described in section 3.2.1. The sub model schematic, including all inputs and outputs, is shown in figure 6 .

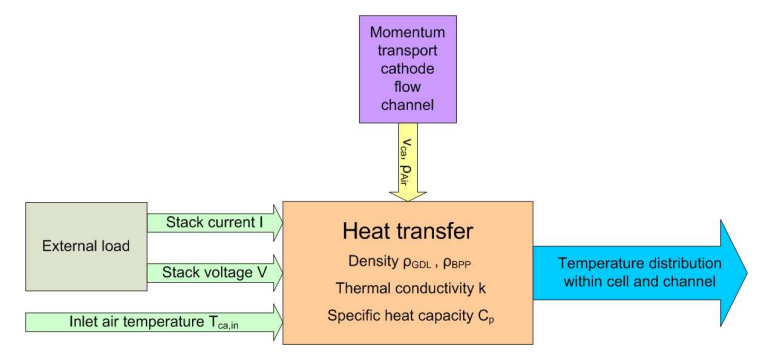

Figure 6: Schematic of the heat transfer model

The energy model is coupled with every other sub-model because temperature has a significant effect on the fluid properties, such as densities of the reactant gases, their dynamic viscosities and also on the diffusivity of water through the MEA.

In the H-100 system heat is produced due to the electrochemical reaction, as well as periodically due to the short circuit that is applied every 10 seconds, as described in section 2.

During a short circuit the useful electrical energy is zero. This means that all the energy is transformed into heat, which increases temperature inside the fuel cell stack. Nevertheless some energy is lost due to circuit and contact resistance, but is neglected at this point. Thus, knowing the short circuit current, as defined later in section 3.2.4, the released heat of one cell can be calculated using equation 3 :

$$
W_{H_{2}}=\frac{H_{L H V}}{2 \cdot F} \cdot I_{s c}(t)=Q_{s c}
$$

\subsubsection{Cathode momentum transport}

In order to describe convective mass transport and heat transfer through the cathode flow channel forced by the fan, the momentum transport has to be determined.

The Reynolds number for the H-100 cathode flow channels at maximum flow velocity turned out to be 120 . Knowing that the air flow through the channels is laminar and that the pressure difference along the channels and the change in fluid density are also very small, the Navier-Stokes equation for an incompressible fluid can be used to model the momentum transfer through the cathode flow channels [13]:

$$
\rho\left(\frac{\partial \vec{v}}{\partial t}+\vec{v} \cdot \nabla \vec{v}\right)=\nabla\left\{-P \vec{I}+\mu\left[\nabla \vec{v}+(\nabla \vec{v})^{\mathrm{T}}\right]\right\}
$$

By solving this equation numerically, the velocity field in the cathode flow channel can be obtained. Figure 7 shows a schematic with all input and output parameters of the sub model.

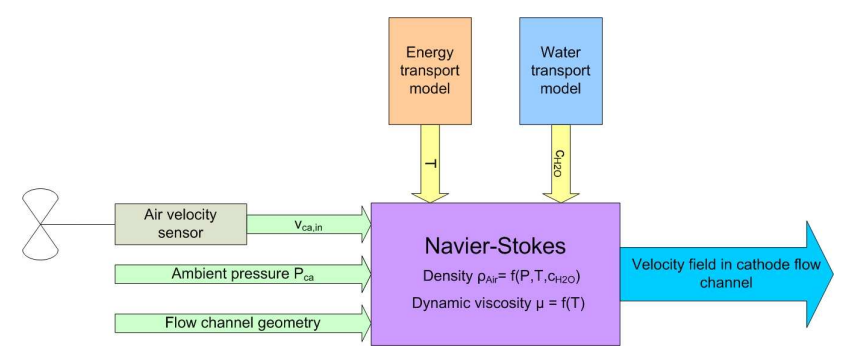

Figure 7: Schematic of the cathode flow model

Since the velocity is dependent on the gas density, which is a function of temperature, pressure and water concentration, this model has to be coupled with the energy and water transport sub model. The boundary conditions for the model are an inlet velocity $v_{0}$ and a constant outlet pressure.

As the cathode air flow determines the amount of heat that is removed from the stack, it has to be controlled by the fan according to the stack temperature. Control strategies can be tested in the model simply by changing the inlet boundary condition from a constant velocity to the desired temperature dependent boundary expression, which is then coupled to the energy transport model.

\subsubsection{Anode momentum transport}

As already described in section 2 the anode is purged periodically every 10 seconds. This results in a convective flux through the anode GDL which removes product water from the GDL and the catalyst layer. Because this pressure driven convective flux occurs in a porous media, the velocity field can be calculated by Darcy's law [13]:

$$
\vec{v}=\frac{-\kappa}{\mu} \nabla P
$$

where $\kappa$ denotes the hydraulic permeability of the porous medium and $\mu$ the dynamic viscosity of the fluid.

The anode inlet gas velocity is determined by the measured mass flow rate. Thus, knowing the velocity and pressure difference from inlet to outlet, the permeability of the GDL, in- 
cluding the microporous layer, turned out to be $10^{-12} \mathrm{~m}^{2}$, which accords to the work of Shi et al. [14] and also is used in the models of Shi \& Wang [15] and Meng \& Wang [16]. The calculated velocity vector is coupled to the water transport model in the anode GDL during a purge to describe the convective mass transport. Figure 8 summarizes the inlet and outlet parameters of the model.

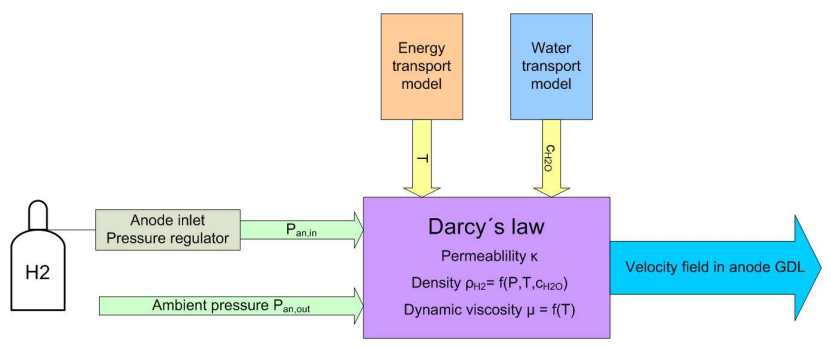

Figure 8: Schematic of the anode flow model

Just as in the cathode flow model, the anode flow model also has to be coupled to the energy and water transport model due to the changes in gas density.

\subsubsection{Water transport}

In order to determine the water transfer rate, which is required for proper water management in the fuel cell and to validate experimental and modeling work, the water mass balance across the fuel cell is needed. The full water mass balance equation is:

$$
\dot{m}_{\mathrm{H}_{2} \mathrm{O}, \mathrm{ca}, \text { in }}+\dot{m}_{\mathrm{H}_{2} \mathrm{O}, \text { an, in }}+\dot{m}_{\mathrm{H}_{2} \mathrm{O}, \text { gen }}=\dot{m}_{\mathrm{H}_{2} \mathrm{O}, \mathrm{ca}, \text { out }}+\dot{m}_{\mathrm{H}_{2} \mathrm{O}, \text { an }, \text { out }}
$$

This equates the water that enters and is generated in the fuel cell to the water that leaves the fuel cell. Water that enters and exits the cell at the cathode is assumed to be in the vapor form, as already explained in section 3.1. The only controversial mass flow would be the anode outlet, where the water could condense. However, this is solved by placing a gas line heater at the exit of the anode, which heats the gas up to about $70^{\circ} \mathrm{C}$ before measuring the dew point temperature which allows for the measurement of all the water leaving the anode. Consequently the mass flow of water is in the vapor form at the location where the dew point temperatures are measured.

Generally the mass flow rate of water vapor can be expressed as a fraction of the dry gas mass flow rate:

$$
\dot{m}_{\mathrm{H}_{2} \mathrm{O}, i, j}=\dot{m}_{i, j_{d}} \cdot x_{\mathrm{H}_{2} O, i, j} \quad\left[\mathrm{~kg} \mathrm{~s}^{-1}\right]
$$

where $i$ stands for anode or cathode and $j$ for inlet or outlet. The determination of the five different terms in equation 11, according to the measurable variables of the test station, is explained below:

1. Anode inlet: The total anode inlet mass flow rate is a sum of the hydrogen mass flow rate and the water vapor mass flow rate, if hydrogen is humidified:

$$
\dot{m}_{a n, i n}=\dot{m}_{H_{2}, a n, i n}+\dot{m}_{H_{2} O, a n, i n} \quad\left[k g ~ s^{-1}\right]
$$

Knowing the amount of water vapor entering hydrogen by measuring the dew point temperature and measuring the inlet mass flow rate of dry hydrogen, the anode inlet mass flow rate of water vapor can be calculated by equation 12 :

$$
\dot{m}_{\mathrm{H}_{2} \mathrm{O}, \text { an,in }}=\dot{m}_{\mathrm{H}_{2}, \text { an,in }} \cdot x_{\mathrm{H}_{2} \mathrm{O}, \text { an,in }} \quad[\mathrm{kg} / \mathrm{s}]
$$

2. Cathode inlet: The total cathode inlet mass flow rate is a sum of oxygen, nitrogen and water vapor mass flow rate:

$$
\dot{m}_{c a, i n}=\dot{m}_{\mathrm{O}_{2}, c a, \text { in }}+\dot{m}_{\mathrm{N}_{2}, \mathrm{ca}, \text { in }}+\dot{m}_{\mathrm{H}_{2} \mathrm{O}, \mathrm{ca}, \text { in }} \quad\left[\mathrm{kg} \mathrm{s}^{-1}\right]
$$

Moreover a mass flow rate of a gas stream can be described by the gas density, the velocity and the cross-sectional area, through which gas flows. As the cathode inlet velocity is measured within the test station the cathode inlet mass flow rate is described by:

$$
\dot{m}_{c a, i n}=\bar{v}_{c a, i n} \cdot A_{c a} \cdot \rho_{c a, i n} \quad\left[k g s^{-1}\right]
$$

where $A_{c a}$ is the cross-sectional area of the fuel cell housing structure within the environmental chamber. Assuming that the median flow velocity $\bar{v}_{c a, i n}$ is constant for wet and dry air, because the change in mass flow rate results from the change in density by adding water, the cathode inlet mass flow rate of water vapor can then be calculated by combining equations 16 and 12 :

$\dot{m}_{\mathrm{H}_{2} \mathrm{O}, c a, i n}=\dot{m}_{a i r, i n, d} \cdot x_{\mathrm{H}_{2} \mathrm{O}, c a, i n}=\bar{v}_{c a, i n} \cdot A_{c a} \cdot \rho_{a i r, d} \cdot x_{\mathrm{H}_{2} \mathrm{O}, c a, i n}$ $\left[k g s^{-1}\right]$

As the cathode inlet air velocity is measured in a housing structure outside the fuel cell stack, but has to be used to model a single channel, the velocity has to be adapted to the smaller flow channel dimensions:

$$
\bar{v}_{c a, i n}=\frac{A_{\text {housing }}}{n_{b p p} \cdot n_{c p p} \cdot A_{c h}} \cdot \bar{v}_{m} \quad\left[m s^{-1}\right]
$$

3. Anode outlet: The total anode outlet mass flow is defined as:

$$
\dot{m}_{\text {an }, \text { out }}=m_{\mathrm{H}_{2}, \text { an }, \text { out }}+m_{\mathrm{H}_{2} \mathrm{O}, \text { an }, \text { out }} \quad\left[\mathrm{kg} \mathrm{s}^{-1}\right]
$$

This mass flow rate of water vapor can be calculated similar to the inlet flow rate, but adding the fact that hydrogen is consumed inside the fuel cell. Therefore the anode outlet mass flow rate of hydrogen is:

$$
\dot{m}_{H_{2}, \text { an,out }}=\left(\dot{m}_{H_{2}, \text { an,in }}-\dot{m}_{H_{2}, \text { an,cons }}\right) \quad\left[\mathrm{kg} \mathrm{s}^{-1}\right]
$$

Using Faraday's law, the consumed hydrogen mass flow rate of one cell is found by:

$$
\dot{m}_{H_{2}, \text { an, cons }}=\frac{M_{\mathrm{H}_{2}}}{2 \mathrm{~F}} \cdot I \quad\left[\mathrm{~kg} \mathrm{~s}^{-1}\right]
$$


Combining equations 12 and 20 the anode outlet mass flow rate of water vapor is described by:

$$
\dot{m}_{\mathrm{H}_{2} \mathrm{O}, \text { an }, \text { out }}=\left(\dot{m}_{\mathrm{H}_{2}, \text { an,in }}-\dot{m}_{\mathrm{H}_{2}, \text { an, cons }}\right) \cdot x_{\mathrm{H}_{2} \mathrm{O}, \text { an,out }} \quad\left[\mathrm{kg} \mathrm{s}^{-1}\right]
$$

4. Cathode outlet: Regarding that only oxygen is consumed at the cathode and the amount of nitrogen stays the same, the total cathode outlet mass flow rate results in:

$$
\begin{array}{r}
\dot{m}_{\text {ca,out }}=\left(\dot{m}_{\mathrm{O}_{2}, \text { ca,in }}-\dot{m}_{\mathrm{O}_{2}, \text { ca,cons }}\right)+\dot{m}_{\mathrm{N}_{2}, \text { ca, in }}+\dot{m}_{\mathrm{H}_{2} \mathrm{O}, \text { ca,out }} \\
{\left[\mathrm{kg} \mathrm{s}^{-1}\right]}
\end{array}
$$

The consumed oxygen mass flow rate of one cell can be calculated using Faraday's law similar to the consumption of hydrogen. The only difference is that the number of electrons per molecule of $\mathrm{O}_{2}$ is 4 .

$$
\dot{m}_{O_{2}, \text { ca,cons }}=\frac{M_{O_{2}}}{4 F} \cdot I \quad\left[k g s^{-1}\right]
$$

According to equation 12, the cathode outlet mass flow rate of water vapor is determined by the following equation:

$$
\dot{m}_{\mathrm{H}_{2} \mathrm{O}, \text { ca,out }}=\dot{m}_{\text {air, out }, \mathrm{d}} \cdot x_{\mathrm{H}_{2} \mathrm{O}, \text { ca,out }} \quad\left[\mathrm{kg} \mathrm{s}^{-1}\right]
$$

where the outlet mass flow rate of dry air can be determined by subtracting the mass flow rate of consumed oxygen from the inlet mass flow rate of dry air:

$$
\dot{m}_{\text {air }, \text { out }, d}=\dot{m}_{\text {air,in,d }}-\dot{m}_{\mathrm{O}_{2}, \text { ca,cons }} \quad\left[\mathrm{kg} \mathrm{s}^{-1}\right]
$$

5. Generated water: The water that is generated in the fuel cell is a product of the reaction of hydrogen and oxygen and is directly proportional to the current passing through the fuel cell stack, based on Faraday's law. Thus, the mass flow rate of generated water results in:

$$
\dot{m}_{\mathrm{H}_{2} \mathrm{O} \text { gen }}=\frac{M_{\mathrm{H}_{2} \mathrm{O}}}{2 \mathrm{~F}} \cdot I \quad\left[\mathrm{~kg} \mathrm{~s}^{-1}\right]
$$

As water is only produced at the cathode catalyst surface, the cathode catalyst boundary condition in the $2 \mathrm{D}$ model is given by the flux of generated water through the active area:

$$
\Phi_{H_{2} O, g e n}=\frac{\dot{m}_{H_{2} O, g e n}}{A_{a c t}} \quad\left[k g s^{-1} m^{-2}\right]
$$

Table 3 depicts the different contributions to the water mass balance equation 11 at $3 \mathrm{~A}$. As it can be seen, the majority of the water enters and leaves the stack at the cathode side, which is relatively large compared to the generated water at this current.

This water mass balance is used to determine the bulk water vapor diffusion coefficient $D_{\mathrm{H}_{2} \mathrm{O}}$ of the MEA, as described in section 4 and to validate experimental results.

\begin{tabular}{lc}
\hline Mass flow rate & Absolute value $\left[\mathrm{mg} \mathrm{s}^{-1}\right]$ \\
\hline$\dot{m}_{\mathrm{H}_{2} \text { O,an,in }}$ & 0.40 \\
$\dot{m}_{\mathrm{H}_{2} \mathrm{O} \text {, ca,in }}$ & 60.12 \\
$\dot{m}_{\mathrm{H}_{2} \mathrm{O} \text {, an, out }}$ & -0.52 \\
$\dot{m}_{\mathrm{H}_{2} \mathrm{O} \text {, ca,out }}$ & -65.60 \\
$\dot{m}_{\mathrm{H}_{2} \mathrm{O} \text {,gen }}$ & 5.60 \\
\hline
\end{tabular}

Table 3: Contributions to the water mass balance equation at $3 \mathrm{~A}$

Since water in a fuel cell is transported by convection, diffusion and is also generated within the cell, the different equations for each transport mechanisms have been combined in a mass balance equation [13]:

$$
\frac{\partial c_{\mathrm{H}_{2} \mathrm{O}}}{\partial t}+\nabla\left(-D_{\mathrm{H}_{2} \mathrm{O}} \nabla c_{\mathrm{H}_{2} \mathrm{O}}\right)=\nabla J_{\mathrm{H}_{2} \mathrm{O}}-\vec{v} \cdot \nabla c_{\mathrm{H}_{2} \mathrm{O}}
$$

The first term on the left-hand side of the equation corresponds to the accumulation of water in the system. The second term accounts for the diffusive transport within the MEA, described by Fick's law. The first term on the right-hand side represents a source flux of water due to the chemical reaction and also the EOD. Finally, the second term on the right-hand side accounts for the convective transport due to a velocity field $\vec{v}$. In the cathode flow channel this field is obtained by coupling the Navier-Stokes momentum transport to the equation system, as described in section 3.2.2, whereas in the anode GDL the momentum transport during a purge is described by Darcy's law, as explained in section 3.2.3.

Water is also transported by the electroosmotic drag from anode to cathode. This flow rate can also be described by Faraday's law, because the EOD is proportional to current [4]:

$$
\dot{m}_{\mathrm{H}_{2} \mathrm{O}, \mathrm{EOD}}=\epsilon \cdot \frac{M_{\mathrm{H}_{2} \mathrm{O}}}{F} \cdot I \quad\left[k g \mathrm{~s}^{-1}\right]
$$

The EOD coefficient $\epsilon$ represents the number of water molecules that are dragged from anode to cathode per proton. This coefficient is determined experimentally, as described in section 4. Regarding the model, the EOD is treated as an internal source flux at the cathode and a sink flux at the anode. A typical water concentration distribution for constant cathode and anode flows is shown in figure 9, where the streamlines describe the flux of water from the cathode catalyst layer to the cathode and anode flow channel. As the H-100 is an open cathode stack, the cathode inlet conditions are ambient. At the anode dry, pure hydrogen enters without humidification.

Figure 10 summarizes all input and output parameters of the model, as well as the influences of the other sub models.

During a short circuit heat and water are produced at the cathode catalyst layer. This mass flow rate of generated water during a short circuit can be calculated using equation 27 and replacing the stack current by the short circuit current. As the short circuit current is a function of time, the root mean square (RMS) current is used to calculate the mass flow rate.

$$
\dot{m}_{\mathrm{H}_{2} \mathrm{O}, \mathrm{gen}, \mathrm{sc}}=\frac{M_{\mathrm{H}_{2} \mathrm{O}}}{2 \mathrm{~F}} \cdot I_{s c} \quad\left[k g \mathrm{~s}^{-1}\right]
$$




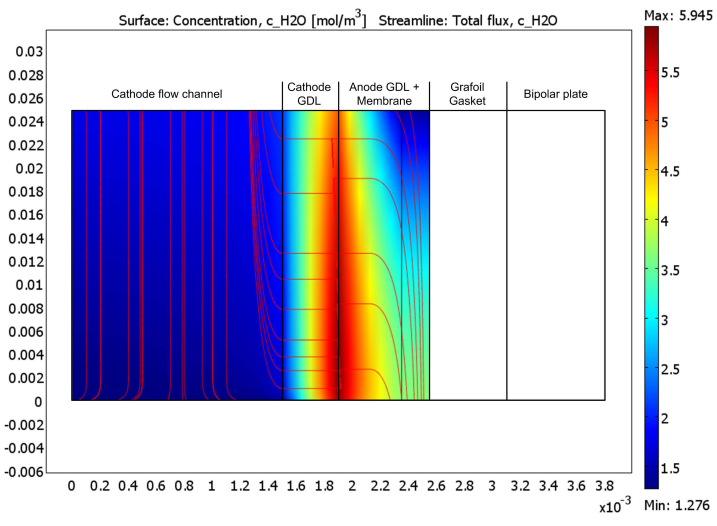

Figure 9: Typical water concentration distribution for constant anode and cathode flows at $5 \mathrm{~A}$ ( $\mathrm{x}$ and $\mathrm{y}$ axis dimensions are in meters)

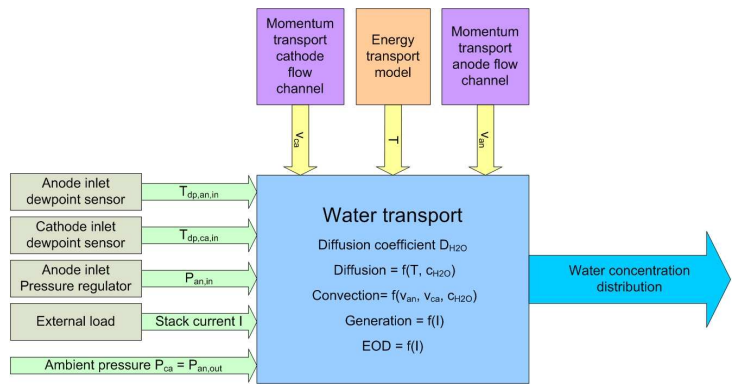

Figure 10: Schematic of the water transport model

where:

$$
I_{s c}=\sqrt{\frac{1}{t_{s c}} \int_{0}^{t_{s c}}\left(I_{s c}(t)\right)^{2} d t}
$$

The RMS short circuit current of the measured $I$ - $t$-curve, shown in figure 11 , results in $23 \mathrm{~A}$.

Table 4 lists the additional model input parameters, such as physical properties, dimensions and constants, which are used in the model.

\section{Experimental determination of coefficients}

The diffusion coefficient of water vapor through the MEA (as stated in section 3.1 also includes all the diffusion layers) is dependent on temperature and water content. In order to develop a mathematical relation between diffusion, temperature and water content, water diffusion has to be separated from the other water transport mechanisms, namely EOD and hydraulic permeation. As the experiments of Husar et al. [11] have shown, water transfer due to hydraulic permeation is at least an order of magnitude lower than that due to the two other transport mechanisms, and therefore can be neglected. To separate diffusion from the EOD, the fuel cell is disconnected from the external circuit and nitrogen is used instead of hydrogen, which also guarantees that no water can be generated due to possible crossover of hydrogen,

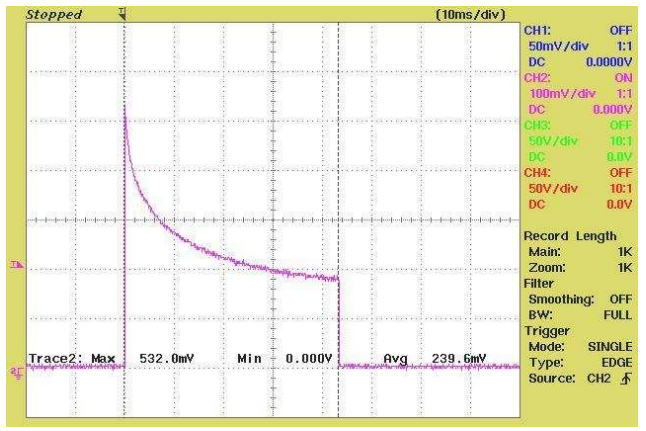

(a) Short circuit duration

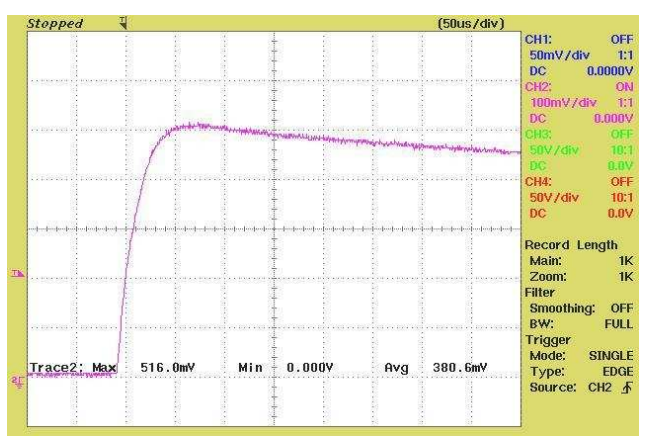

(b) Rising edge

Figure 11: I-t-plot of a short circuit

which would generate water at the cathode side. The experiment was carried out with a dry anode and a wet cathode. The diffusive water mass flux across the membrane is the outlet water mass flux at the dry side which should equal the difference between inlet to outlet water mass flux of the wet side. Since the H-100 is an open cathode fuel cell it is difficult to perform a similar diffusion experiment in the opposite direction, with a wet anode and a dry cathode. However, random tests at stable points where the anode humidity was higher than at the cathode side have shown a direction independence of the diffusion coefficient. The dew point temperature of the wet cathode was kept constant at $20^{\circ} \mathrm{C}$, which means that the partial pressure of water vapor in air does not change with temperature, unlike with using a constant relative humidity. The ambient temperature was increased from 30 to $50{ }^{\circ} \mathrm{C}$ with a step size of $10^{\circ} \mathrm{C}$ by using an environmental chamber. At each point enough time was given for the anode dew point temperature to become stable, so that a steady state can be assumed. The chamber temperature then equals the stack temperature. Moreover, the maximum cathode flow rate was applied in order to minimize the concentration difference from inlet to outlet at the wet side.

Figure 12 shows the membrane diffusivity of water vapor at different temperatures. Compared to the work of Springer et al. [1] the experimentally obtained diffusion coefficient is smaller. This might be due to the different membrane type and thickness used in this work. However, similar results were found by McKay \& Stefanopoulou [17], who also performed in-situ 


\begin{tabular}{|c|c|c|}
\hline Description & Value & Unit \\
\hline Active catalyst area, $A_{a c t}$ & 0.00225 & $m^{2}$ \\
\hline Bipolar plate density, $\rho_{B P P}$ & 1850 & $\mathrm{~kg} \mathrm{~m}^{-3}$ \\
\hline Bipolar plate thermal conductivity, $k_{B P P}$ & 14 & $W K^{-1} m^{-1}$ \\
\hline Cross-section channel, $A_{c h}$ & $1.5 \times 10^{-6}$ & $m^{2}$ \\
\hline Faraday constant, $F \quad \ldots$. & 96487 & $\mathrm{Cmol}^{-1}$ \\
\hline GDL density, $\rho_{G D L}$ & 440 & $\mathrm{~kg} \mathrm{~m}^{-3}$ \\
\hline GDL permeability, $\kappa_{G D L}$ & $1 \times 10^{-12}$ & $m^{2}$ \\
\hline GDL porosity, $\epsilon_{G D L}$ & 0.78 & \\
\hline GDL thermal conductivity inplane, $k_{G D L}$ & 21 & $W K^{-1} m^{-1}$ \\
\hline GDL thermal conductivity through-plane, $k_{c}$ & 1.7 & $W K^{-1} m^{-1}$ \\
\hline GDL thickness & $4 \times 10^{-4}$ & $m$ \\
\hline Number of bipo & 21 & \\
\hline Number of cells, $n_{\text {cell }}$ & 20 & \\
\hline Number of channels per plate, $n_{c p p}$ & 51 & \\
\hline Universal gas constant, $R$ & 8.314 & $J m l^{-1} K^{-1}$ \\
\hline
\end{tabular}

Table 4: Physical parameters and properties

measurements of the diffusion coefficient with a fuel cell stack.

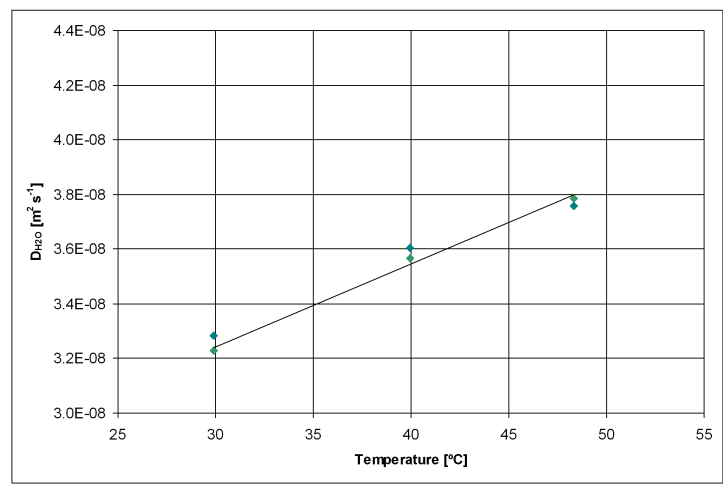

Figure 12: Membrane Diffusivity as a function of stack temperature

In order to determine the EOD coefficient experimentally, diffusive water transport through the membrane has to be minimized. This can be obtained by keeping the water concentration on both sides equal and as close to $100 \%$ relative humidity as possible, which is achieved by setting the same dew point temperature for the anode and cathode inlets. The measured EOD coefficient slightly increases from 0.47 to 0.48 by increasing the stack current from 1 to $3 \mathrm{~A}$, which is in accordance with the data of Husar et al. [11], but their test was performed at higher current densities and using a thicker membrane.

To determine a specific heat capacity for the stack, a constant current is drawn for a short period of time, and the stack temperature evolution is measured. The test resulted in a specific heat capacity of $1260 \mathrm{~J} \mathrm{~kg}^{-1} \mathrm{~K}^{-1}$. A similar value is also used in the heat transfer model of He et al. [18].

\section{Results and Discussion}

\subsection{Steady-state validation}

By validating the steady-state model, the general model settings such as the boundary conditions, applied physical phenomena or experimentally determined coefficients can be checked. Therefore, experimental data of the H-100 fuel cell stack, directly obtained from laboratory tests, were compared to the simulation results. The initial conditions were a humidified anode and cathode, and a constant fan flow rate. Even though the regular working conditions of the H-100 suggest a dry anode, these tests were performed in order to check the model behaviour even under conditions that don't appear in a normal operation. The stack current was stepwise increased from 1 to 3 A. Figure 13 shows the measured and modeled values of the cathode and anode outlet water concentrations, as well as the fuel cell stack temperature at different currents.

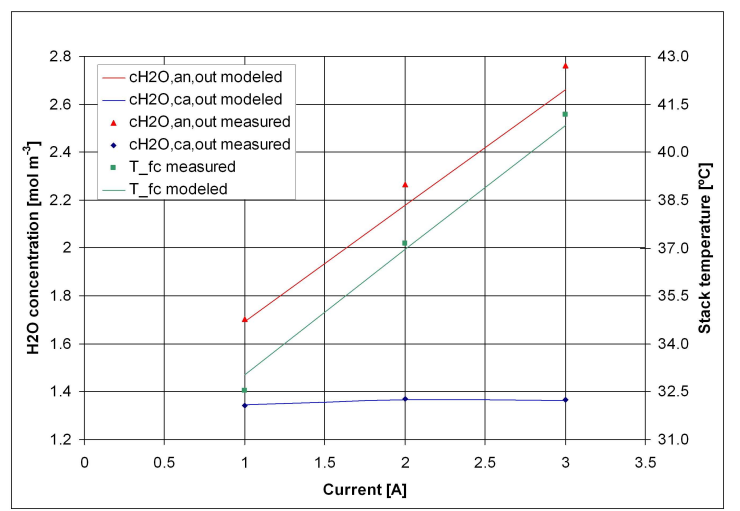

Figure 13: Anode and cathode outlet water concentration as a function of current

\subsection{Dynamic validation}

The model has also been compared to dynamic experiments performed with the studied PEM fuel cell stack. These tests have shown that the model is able to give a proper dynamic representation of the actual stack behavior. Figure 14 shows the comparison of the simulated cathode outlet water concentration with the measurement data, when changing the cooling fan velocity at a constant working point of $5 \mathrm{~A}$. 


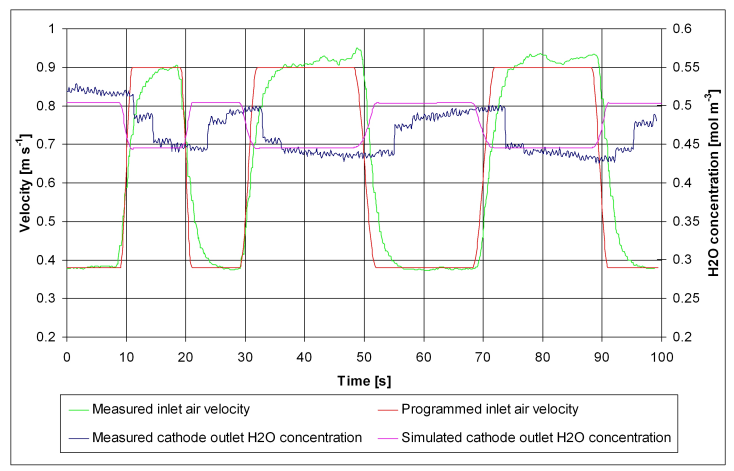

Figure 14: Dynamic validation - Humidity fan test

The test results show that there is a delay in the cathode outlet dew point measurement, which is due to the response time of the dew point sensor used in this experiment. However, disregarding this unavoidable measurement error, the simulated cathode outlet water concentration gives a good representation of the experimental results.

The second validation parameter is the stack temperature, which was also measured and simulated within the same test. The comparison is illustrated in figure 15 .

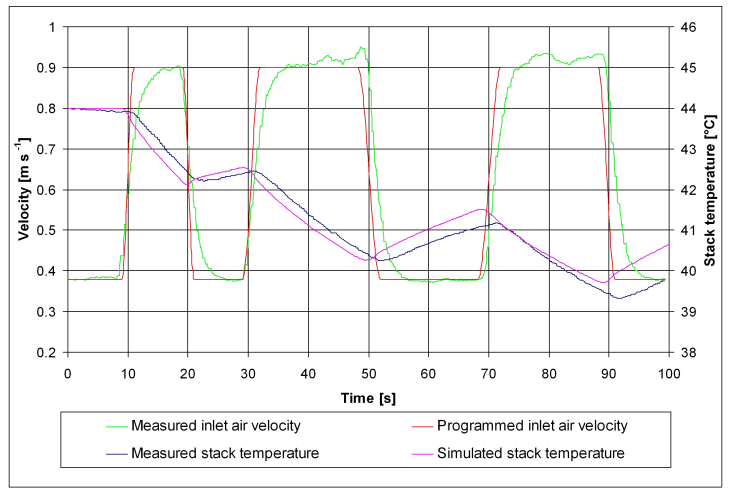

Figure 15: Dynamic validation - Temperature fan test

A delay in the measured stack temperature can be noticed here as well. This is not only due to the response time of the sensor but also due to the differences between the programmed velocity curve and the measured curve, which shows a smaller slope at low velocities and therefore the temperature changes slower than in the model. Regarding the temperature gradients, the model matches the experiment, especially during the cooling phase. The modeled fuel cell stack temperature increases faster than the measured temperature when the fan velocity is reduced. The slower increase in the measured temperature could be caused by small amounts of convective and radiative heat removal from the stack, which is not included in the model.

The conclusion of both tests is that the model demonstrates an accurate dynamic representation of the fan.

\subsection{Sensitivity Analysis}

In order to quantify the sensitivity of the input variables of the model, a sensitivity analysis was performed at different cur- rent set points. Table 5 shows the model input variable settings and the resulting output variable values at a stack current of $3 \mathrm{~A}$. It also includes the variable variations for the sensitivity analysis. The variation of the anode and cathode inlet water mass fraction represents a variation in the measured inlet dew point temperature of $1{ }^{\circ} \mathrm{C}$, from 20 to $21^{\circ} \mathrm{C}$ at the cathode and from 25 to $26^{\circ} \mathrm{C}$ at the anode. The big difference between anode and cathode water mass fraction is not only due to the difference in dew point temperature but rather due to the much higher gas flow rate at the cathode. Since the anode inlet temperature has no effect it is not included in this analysis.

By changing the input variables $\left(\xi_{\text {in }}\right)$, according to the variable variations $\left(\Delta \xi_{\text {in }}\right)$, defined in table 5 , the impact of input signal offsets or variable deviations on each output variable can be observed. Table 6 shows the sensitivity matrix, depicting the resulting output variable values for each input variable variation with the respective relative sensitivity $s$.

As a result it can be seen that increasing the cathode inlet dew point temperature by $1{ }^{\circ} \mathrm{C}$ has almost the same effect on the anode outlet water mass fraction as increasing the anode inlet dew point temperature, however not vice versa. Also the stack current has a similar effect on the anode outlet water mass fraction. Moreover, an increase of the cathode inlet air velocity of $0.1 \mathrm{~m} \mathrm{~s}^{-1}$ has the same effect as a $1^{\circ} \mathrm{C}$ change in the ambient temperature at these conditions. These observations indicate that the cathode mass flux dominates the energy and mass balance in this stack. All variables show very low sensitivity to a variation of the stack voltage, but are sensitive to a change in the stack current. Repeating the experiment at higher and lower stack currents leads to similar variable sensitivities.

\section{Conclusion}

A two-dimensional, non-isothermal, dynamic model of a $100 \mathrm{~W}$ open cathode, self-humidified PEM fuel cell system has been developed with respect to water and heat transport within the cell. The crucial coefficients for water transport, namely the diffusion and the EOD coefficient, have been determined experimentally. The diffusivity of water vapor through the membrane at $30^{\circ} \mathrm{C}$ was determined to be $3.3 \times 10^{-8} \mathrm{~m}^{2} \mathrm{~s}^{-1}$ and increases by $3 \times 10^{-10} \mathrm{~m}^{2} \mathrm{~s}^{-1}$ per ${ }^{\circ} \mathrm{C}$ with increasing temperature to $50{ }^{\circ} \mathrm{C}$. The EOD coefficient was found to be 0.47 to 0.48 water molecules per proton at stack currents from 1 to $3 \mathrm{~A}$. Moreover, the bulk specific heat capacity for one cell unit, consisting of a MEA plus a bipolar plate, was experimentally determined to be $1260 \mathrm{~J} \mathrm{~kg}^{-1} \mathrm{~K}^{-1}$. The model has been validated by using experimental data directly obtained from laboratory tests with the investigated fuel cell stack, which has shown that the model predictions match the experimental data well. The model is kept simple and is capable of representing system specific control mechanisms for water and heat management, as demonstrated within the dynamic validation. As it combines most of the physical phenomena that occur within a PEM fuel cell, it permits for a comprehensive study of these control mechanisms. However, the model can still be improved by including charge transfer, two phase flow characteristics as well as temperature driven water transport. Moreover, further experiments are needed to 


\begin{tabular}{l|ccccccc}
\hline & $T_{c a}\left[{ }^{\circ} \mathrm{C}\right]$ & $T_{a n}\left[{ }^{\circ} \mathrm{C}\right]$ & $x_{H 2 O, c a}$ & $x_{H 2 O, a n}$ & $v_{c a}\left[\mathrm{~m} \mathrm{~s}^{-1}\right]$ & $I_{\text {stack }}[A]$ & $V_{\text {stack }}[\mathrm{V}]$ \\
\hline in & 30.00 & 30.00 & 0.01475 & 0.23937 & 0.4 & 3.0 & 13.5 \\
out & 35.84 & 38.10 & 0.01577 & 0.50157 & - & - & - \\
\hline$\Delta \xi_{\text {in }}$ & 1.0 & - & 0.00096 & 0.01424 & 0.1 & 0.1 & 0.1 \\
\hline
\end{tabular}

Table 5: Input and output variable values and input variable variations

\begin{tabular}{|c|c|c|c|c|c|c|c|c|}
\hline$\xi_{\text {in }}$ & $\begin{array}{c}T_{\text {ca,out }} \\
{\left[{ }^{\circ} \mathrm{C}\right]}\end{array}$ & $\begin{array}{c}s\left(T_{\text {ca,out }}\right) \\
{[\%]}\end{array}$ & $\begin{array}{c}T_{\text {an,out }} \\
{\left[{ }^{\circ} \mathrm{C}\right]}\end{array}$ & $\begin{array}{c}s\left(T_{\text {an,out }}\right) \\
{[\%]}\end{array}$ & $x_{H 2 O, c a, \text { out }}$ & $\begin{array}{c}s\left(x_{H 2 O, \text { ca,out }}\right) \\
{[\%]}\end{array}$ & $x_{H 2 O, \text { an,out }}$ & $\begin{array}{c}s\left(x_{H 2 O, \text { an,out }}\right) \\
{[\%]}\end{array}$ \\
\hline$T_{c a, \text { in }}$ & 36.86 & 2.85 & 39.10 & 2.62 & 0.015788 & 0.13 & 0.502341 & 0.15 \\
\hline$x_{H 2 O, c a, i n}$ & 35.84 & 0.00 & 38.10 & 0.00 & 0.016744 & 6.20 & 0.509306 & 1.54 \\
\hline$x_{H 2 O, a n, i n}$ & 35.84 & 0.00 & 38.10 & 0.00 & 0.015789 & 0.14 & 0.509386 & 1.56 \\
\hline$v_{c a, i n}$ & 34.84 & -2.80 & 37.30 & -2.10 & 0.015570 & -1.25 & 0.499355 & -0.44 \\
\hline$I_{\text {stack }}$ & 36.04 & 0.56 & 38.37 & 0.71 & 0.015802 & 0.22 & 0.510875 & 1.85 \\
\hline$V_{\text {stack }}$ & 35.79 & -0.14 & 38.03 & -0.18 & 0.015765 & -0.02 & 0.501492 & -0.02 \\
\hline
\end{tabular}

Table 6: Sensitivity matrix at $3 \mathrm{~A}$

observe the dynamic effect of water storage in the membrane and the anode GDL, and finally include them in the model. The developed model is intended to be used to simulate and study the effects of water transport and its influence on the system performance, and to develop new water management control strategies, that are strongly demanded, as recent papers have shown. The model is easy to handle by the user-friendly CFD software COMSOL Multiphysics, and can be easily extended. Furthermore, it is applicable to other PEM fuel cell systems, following the developed modeling strategy and performing the experiments in order to determine the specific coefficients.

\section{Acknowledgements}

All the experimental tests were performed at the Fuel Cells Laboratory of the Institut de Robòtica i Informàtica Industrial (CSIC-UPC, Barcelona) and only possible due to its advanced equipment and proficient technical staff. This work is partially funded by the project of CICYT DPI2007-62966 MICINN, DPI2010-15274 MICINN and the project AECID A/026279/09 and supported from a predoctoral scholarship JAE-intro from CSIC.

\section{References}

[1] T. E. Springer, T. A. Zawodzinski, S. Goftesfeld, Polymer electrolyte fuel cell model, Journal of The Electrochemical Society 138 (1991) 2334 2342 .

[2] I. Hussaini, C. Wang, Dynamic water management of polymer electrolyte membrane fuel cells using intermittent rh control, Journal of Power Sources 195 (2010) 3822 - 3829.

[3] W. Dai, H. Wanga, X.-Z. Yuan, J. J. Martin, D. Yang, J. Qiao, J. Mab, A review on water balance in the membrane electrode assembly of proton exchange membrane fuel cells, International Journal of hydrogen energy 34 (2009) $9461-9478$.

[4] F. Barbir, PEM Fuel cells: Theory and Practice, Elsevier Academic Press, 2005.

[5] V. Gurau, H. Liu, S. Kakac, Two-dimensional model for proton exchange membrane fuel cells, AIChE Journal 44 (1998) 2410 - 2422.

[6] H. Ju, H. Meng, C.-Y. Wang, A single-phase, non-isothermal model for pem fuel cells, International Journal of Heat and Mass Transfer 48 (2005) $1303-1315$.
[7] Y. Wang, C.-Y. Wang, A nonisothermal, two-phase model for polymer electrolyte fuel cells, Journal of The Electrochemical Society 153 (2006) A1193 - A1200.

[8] S. Basu, C.-Y. Wang, K. S. Chen, Phase change in a polymer electrolyte fuel cell, Journal of The Electrochemical Society 156 (2009) B748 B756.

[9] S. Basu, J. Li, Chao-YangWang, Two-phase flow and maldistribution in gas channels of a polymer electrolyte fuel cell, Journal of Power Sources 187 (2009) $431-443$.

[10] Z. Shi, X. Wang, Two-dimensional pem fuel cells modeling using comsol multiphysics, in: G. Petrone, G. Cammarata (Eds.), Modeling and Simulaton, In Tech Education and Publishing, 2008, pp. 679 - 688.

[11] A. Husar, A. Higier, H. Liu, In situ measurements of water transfer due to different mechanisms in a proton exchange membrane fuel cell, Journal of Power Sources 183 (2008) 240 - 246.

[12] E. A. Müller, A. G. Stefanopoulou, Analysis, modeling, and validation for the thermal dynamics of a polymer electrolyte membrane fuel cell system, Excerpt from the third International Conference on Fuel Cell Science, Engineering and Technology 2005, Ypsilanti, Michigan, USA (2005).

[13] COMSOL, COMSOL Multiphysics Version 3.5 Documentation, Chemical Engineering Module, 2008.

[14] Y. Shi, J. Xiao, M. Pana, R. Yuan, A fractal permeability model for the gas diffusion layer of pem fuel cells, Journal of Power Sources 160 (2006) $277-283$.

[15] Z. Shi, X. Wang, Comparison of darcy's law, the brinkman equation, the modified n-s equation and the pure diffusion equation in pem fuel cell modeling, Excerpt from the Proceeding of the COMSOL Conference 2007, Boston (2007).

[16] H. Meng, C.-Y. Wang, Model of two-phase flow and flooding dynamics in polymer electrolyte fuel cells, Journal of The Electrochemical Society 152 (2005) 1733 - 1741.

[17] D. McKay, A. Stefanopoulou, Parameterization and validation of a lumped parameter diffusion model for fuel cell stack membrane humidity estimation, Proceeding of the American Control Conference (2004).

[18] G. He, Y. Yamazaki, A. Abudula, A three-dimensional analysis of the effect of anisotropic gas diffusion layer thermal conductivity on the heat transfer and two-phase behavior in a proton exchange membrane fuel cell, Journal of Power Sources 195 (2010) 1551 - 1560. 